\title{
Cancer care heavyweights band together
}

Three prominent Boston cancer care facilities announced 17 January that they were joining forces to produce one of the largest cancer care networks in the United States. The Dana-Farber Cancer Institute, Brigham and Women's Hospital, and Massachusetts General Hospital (MGH) will form the Dana-Farber/Partners Cancer Care, Inc. The name refers to Partners Healthcare System, a network of more than 500 primary care physicians formed two years ago by $\mathrm{MGH}$ and the Brigham hospital. The new venture will be run by an eight-member board drawn equally from Dana-Farber and Partners.

"The main reason [for the joint IMAGE venture] is to proUNAVAILABLEuniform cancer FOR care program for COPYRIGHT adults in this reREASONS says David Nathan, president of Dana-

Farber and CEO of

David Nathan, CEO the new entity. of Dana-Farber/ "There was this Partners Cancer feeling that we Care, Inc. were working very hard to establish

high-quality care, but that we were working in a microcosm."

That sense of isolation was heightened by the widely publicized death of Boston Globe health columnist Betsy Lehman from a dosage mix-up during experimental chemotherapy at Dana-Farber in November of 1994. The tragic event "highlighted the difficulties in running a free-standing institution," according to Vincent DeVita, Director of the Yale Cancer Center and chair of the committee formed to investigate the incident. Despite the appearance, however, the joining of Dana-Farber with MGH and the Brigham is not a result of the problems. In fact, negotiations between Partners and Dana-Farber were under way several months before Lehman's death. "We were stunned," says Samuel Thier, President of Partners Healthcare Systems and MGH, "but the troubles had nothing to do with [the joint venture]. Dana-Farber is a quality institution, and we are very proud to be associated with them."

A more urgent reason for the venture is economic. "Another goal is to try to make all this less expensive," says Nathan. "One way to do so is through the sharing of resources." One immediate plan is the transfer of Dana-Farber's 57 inpatient hospital beds across the street to the Brigham, and the Brigham's ambulatory care facilities to the DanaFarber, an arrangement similar to that of the pediatric oncology program shared by Dana-Farber and Children's Hospital.

Although some have voiced concern that the new venture will squeeze out other area researchers and programs not directly involved, both Thier and Nathan emphasize that the new arrangement does not preclude other collaborations. "This arrangement does not exclude us from any other collaborations we want to make in cancer care or treatment or teaching," says Nathan. "We can collaborate with any of our colleagues."

Once final details are ironed out and the necessary approvals obtained, it is anticipated that the programs planned for the new venture will be operating in about a year.

FinTAN R. STEELE

\section{Genentech wins battle over European anticlot drug patent}

One of the longest running biotechnology patent disputes drew to an end in December when the European Patent Office (EPO) upheld US biotechnology giant Genentech's patent on tissue plasminogen activator (tPA).

tPA, which breaks down blood clots, was the first major commercially successful biotechnology product. But ever since it went on the market almost ten years ago, the manufacturer, Genentech of San Francisco, has been fighting to maintain its patent. The objections arose because the patent covers the process for preparing tPA, and, in effect, prevents another company from selling any modified form of tPA that has the same biochemical action in the body.

The argument began when Genentech beat the Genetics Institute in Cambridge, Massachusetts, in the race to unravel the structure of tPA. It became a cause célebre of the biotech industry, largely because it highlighted so many of the ambiguities in patenting substances that are based on copies of proteins found naturally in the human body.

One of the main opponents of the Genentech patent was Wellcome (now part of Glaxo Wellcome), which licensed the Genetics Institute's version of tPA. Although it stopped worldwide development of tPA after losing the patent battle in the United States in 1990, Wellcome and seven other companies continued to contest Genentech's European patent.

In December 1995, EPO rejected the final appeal against the patent made by Wellcome, Boehringer Mannheim of

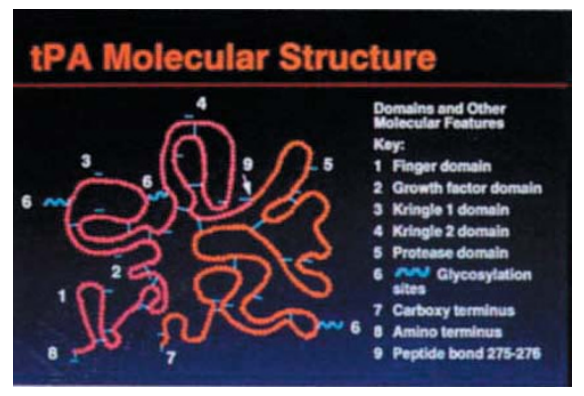

Germany, and Celltech of the United Kingdom. This leaves Genentech with only one outstanding appeal (in Japan).

Phillip Ansell, Patent Manager at Celltech, says that, like Wellcome, his company no longer has a commercial interest in TPA. "But we decided to appeal because the issues raised are so fundamental." He points out that although the Genentech patent stands, it was modified quite considerably as a result of the appeal. "What we got from the appeal was clarity," he says. "If we have similar patent applications there is now some case law to help us in drafting them." Ansell also says that this case, along with others, will give the industry nıore confidence to invest.

Stephen Raines, Genentech's vice oresident of intellectual property, expressed satisfaction at the ruling. "This means that you can't change one amino acid and get round the patent," he says. "Anyone producing a drug with the same biochemical performance infringes our patent."

NuAla MORAN London 